\title{
Effect of Beta Low Irradiation Doses on the Micromechanical Properties of Surface Layer of LDPE
}

\author{
David Manas ${ }^{1, a}$, Martin Ovsik ${ }^{1, b}$, Miroslav Manas ${ }^{1, c}$, Michal Stanek $^{1, d}$, Karel \\ Kocman $^{1, \mathrm{e}}$, Martin Bednarik ${ }^{1, \mathrm{f}}$, Marcela Spanhelova ${ }^{1, \mathrm{~g}}$ \\ ${ }^{1}$ Tomas Bata University in Zlin, TGM 5555, 76001 Zlin, Czech Republic \\ admanas@ft.utb.cz, bovsik@ft.utb.cz, 'cmanas@ft.utb.cz, ${ }^{d}$ stanek@ft.utb.cz, ${ }^{\mathrm{e}} \mathrm{k}$ ocman@ft.utb.cz, \\ 'bednarik@ft.utb.cz, ${ }^{9}$ spanhelova@ft.utb.cz
}

Keywords: nanohardness, Low-density polyethylene, irradiation cross - linking, DSI - Depth Sensing Indentation, surface layer.

\begin{abstract}
The experimental study deals with the effect of modification of the surface layer by irradiation cross-linking on the micromechanical properties of the low-density polyethylene (LDPE) tested using the instrumented nanohardness test. The surface layer of LDPE specimen made by injection technology was modified by irradiation cross-linking using beta irradiation, which significantly influences micromechanical properties of the surface layer. Compared to the heat and chemical-heat treatment of metal materials (e.g. hardening, nitridation, case hardening), crosslinking in polymers affects the surfaces in micro layers. These micromechanical changes of the surface layer are observed in the instrumented microhardness test. Our research confirms the comparable properties of surface layer of irradiated LDPE with highly efficient polymers. The subject of this research is the influence of irradiation dosage on the changes of micromechanical properties of surface layer of LDPE.
\end{abstract}

Introduction. Low-density polyethylene (LDPE) is a commodity polymer used extensively in extrusion operations such as coating, blown film, blow molding, and foaming. Extrusion of LDPE foams by direct gas injection or the so-called physical foaming can be separated in to five distinctive steps, i.e. melting of the solid LDPE pellets, injection and mixing of the liquid gas in the molten LDPE, cooling and shaping of the melt into the expansion condition, foaming of the melt by the expanding gas and finally cooling of the foam. Although viscosity and melting/crystallization behavior plays an important role in each or most of these process steps, the gas expansion is the crucial step in the foam process. In order to obtain a good foam quality (regular fine cell size and high closed cell content), the gas laden melt needs to be cooled down to a temperature close to the crystallization temperature of the semi-crystalline polyolefin to increase the melt viscosity and reduce the time needed for the transition from melt to solid phase. In practice, this means for semicrystalline LDPE that the temperature of the melt at the die exit is always a few degree centigrade above the crystallization temperature [1-4].

\section{Experimental}

Materials. For this experiment High Density Polyethylene HDPE DOW - HDPE 25055E, DOW - Chemical company, USA (unfilled, HDPE) was used. The prepared specimens were irradiated with doses of 0, 33, 66 and 99 kGy at BGS Beta-Gamma Service GmbH \& Co. KG, Germany.

The samples were made using the injection molding technology on the injection molding machine Arburg Allrounder 420C. Processing temperature $220-280{ }^{\circ} \mathrm{C}$, mold temperature $70{ }^{\circ} \mathrm{C}$, injection pressure $65 \mathrm{MPa}$, injection rate $45 \mathrm{~mm} / \mathrm{s}$.

Instrumented nanohardness tests were done using a Nanoindentation Tester (NHT2) Opx/Cpx , CSM Instruments (Switzerland) according to the CSN EN ISO 14577-1. Load and unload speed was $20 \mathrm{mN} / \mathrm{min}$. After a holding time of $90 \mathrm{~s}$ at maximum load $10 \mathrm{mN}$ the specimens 
were unloaded. The specimens were glued on metallic sample holders. Fifteen specimens were tested and average values are reported.

The indentation hardness $\mathrm{H}_{\mathrm{IT}}$ was calculated as maximum load to the projected area of the hardness impression according to [3-7]:

$$
H_{I T}=\frac{F_{\max }}{A_{p}}
$$

The indentation modulus is calculated from the Plane Strain modulus using an estimated sample Poisson's ratio:

$$
E_{I T}=E^{*} \cdot\left(1-v_{s}^{2}\right)
$$

Determination of indentation creep $\mathrm{C}_{\mathrm{IT}}$ (as can be seen at Fig. 1):

$$
C_{I T}=\frac{h_{2}-h_{1}}{h_{1}} \cdot 100
$$

Where $h_{1}$ is the indentation depth at time $t_{1}$ of reaching the test force (which is kept constant), $h_{2}$ is the indentation depth at time $t_{2}$ of holding the constant test force [5-6].

Elastic part of the indentation work $\eta_{\text {IT }}$ (as can be seen at Fig. 2):

$$
\eta_{I T}=\frac{W_{\text {elast }}}{W_{\text {total }}} \cdot 100
$$

with

$$
W_{\text {total }}=W_{\text {elast }}+W_{\text {plast }}
$$

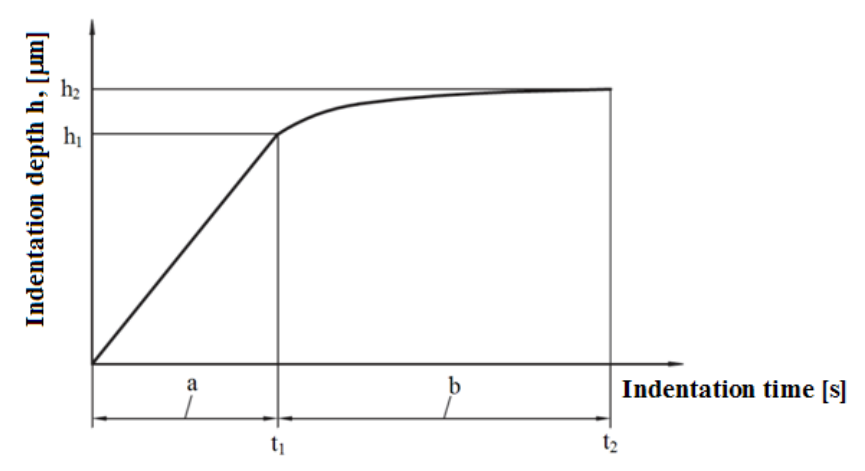

Fig. 1 Expression of indentation creep

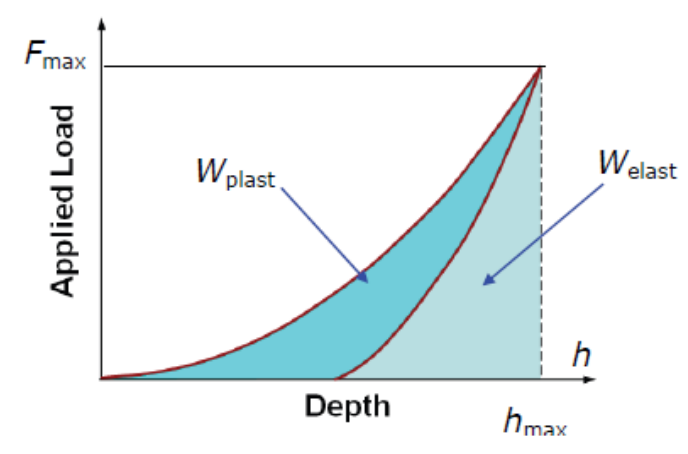

Fig. 2 Indentation work

\section{Results and discussion}

The values measured during the nanohardness test showed that the highest values of indentation hardness were found for the non-irradiated LDPE. On the contrary, the lowest values of indentation hardness were obtained for LDPE irradiated by a dose of $33 \mathrm{kGy}$ (by $25 \%$ lower in comparison with the non-irradiated LDPE), as can be seen at Fig. 3.

Higher radiation dose does not influence significantly the nanohardness value. An indentation hardness increase of the surface layer is caused by irradiation cross-linking of the tested specimen. A closer look at the nanohardness results reveals that when the highest radiation doses are used, nanohardness decreases which can be caused by radiation indusced degradation of the material.

Radiation, which penetrated through specimens gradually formed cross-linking (3D net), first in the surface layer and then in the total volume, which resulted in considerable changes in specimen behavior.

According to the results of measurements of nanohardness, it was found that the lowest values of indentation modulus of elasticity were achieved at the LDPE irradiated with dose of $33 \mathrm{kGy}$ (by $12 \%$ lower than compared with non-irradiated LDPE). On the contrary, the highest values of the indentation modulus of elasticity were found for non-irradiated LDPE as is seen at Fig. 4. 


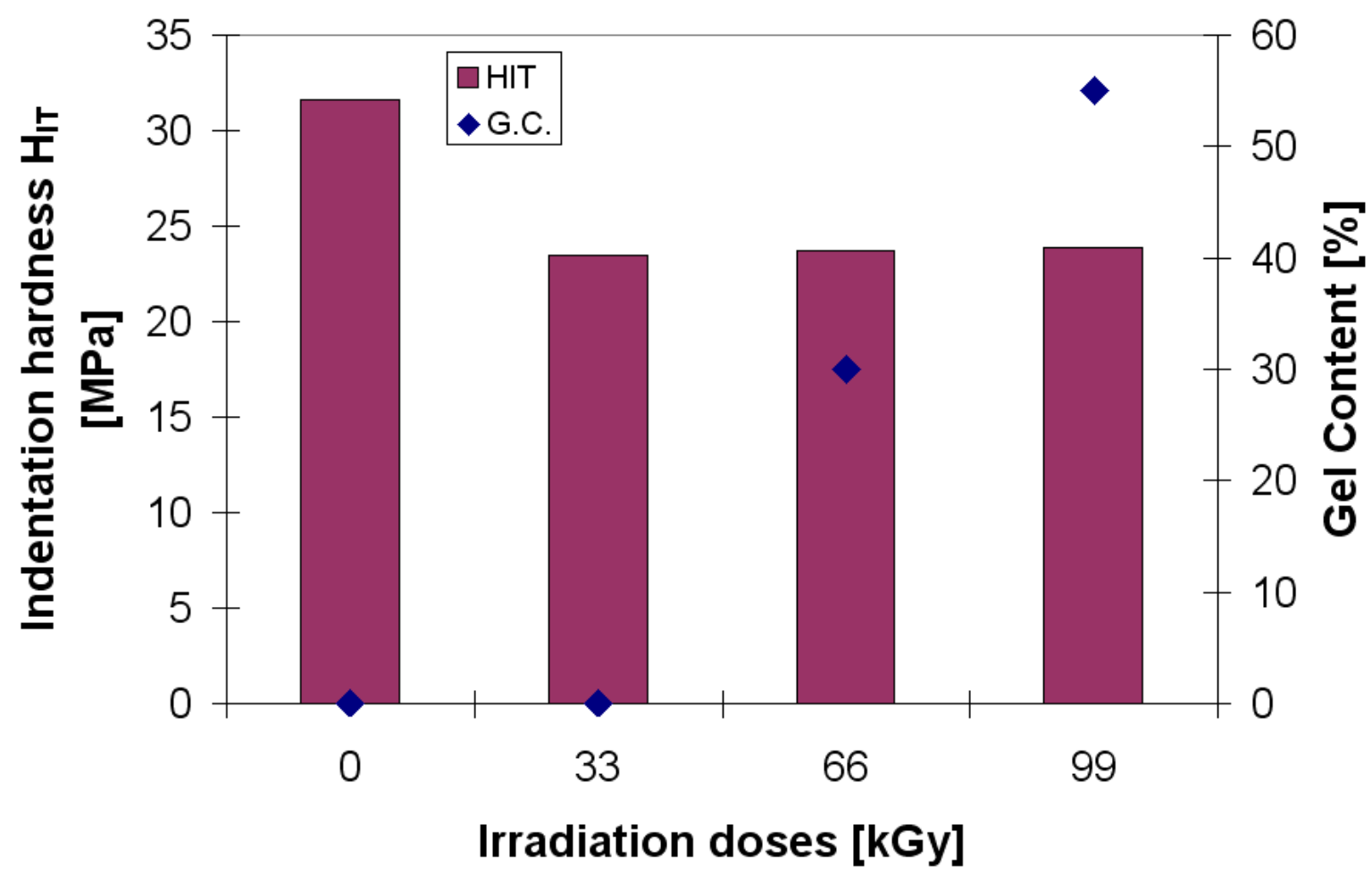

Fig. 3 Hardness $\mathrm{H}_{\mathrm{IT}}$ vs. irradiation doses of LDPE

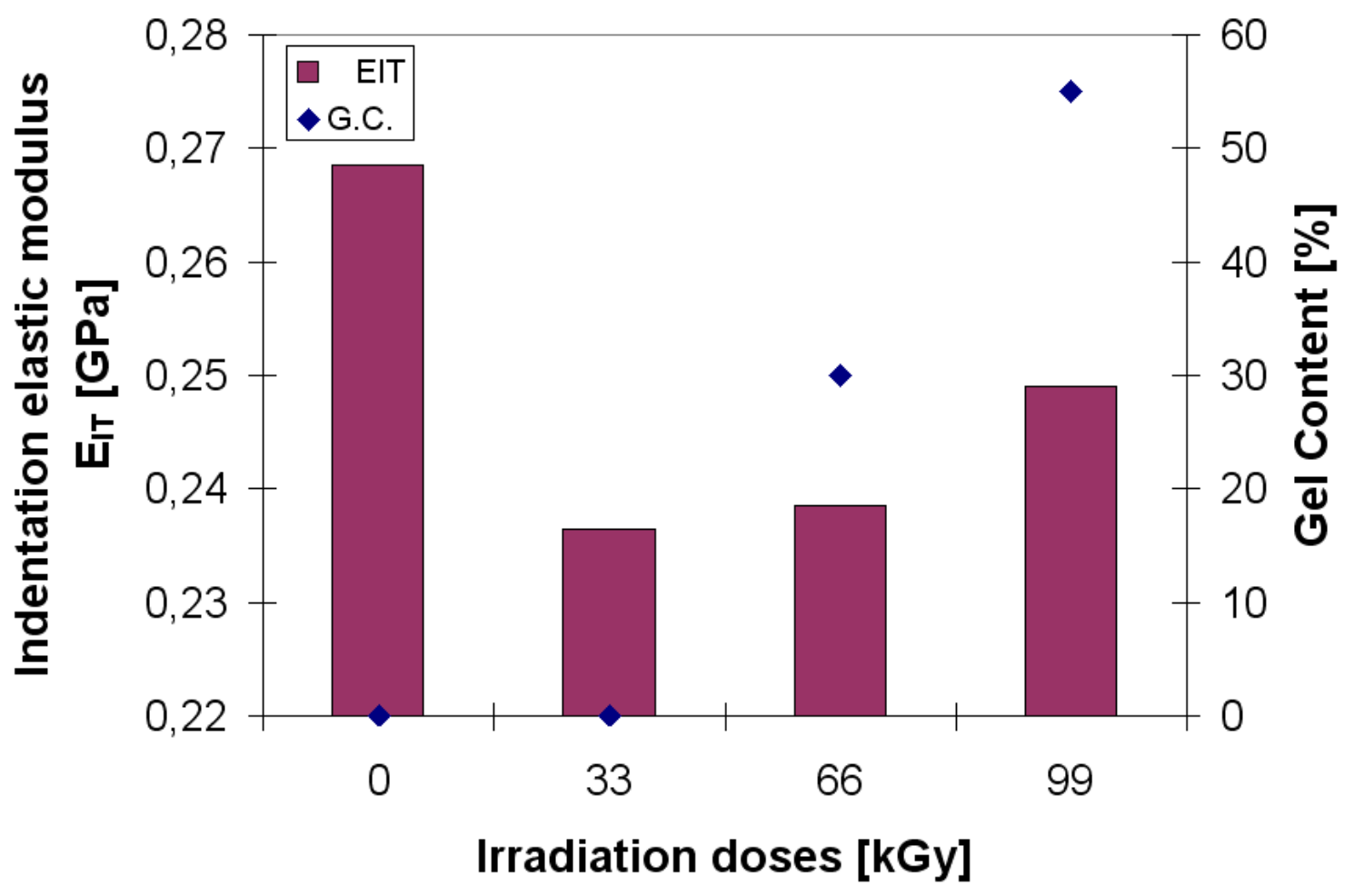

Fig. 4 Indentation modulus $\mathrm{E}_{\mathrm{IT}}$ vs. irradiation doses of LDPE

According to the results of measurements of nanohardness, it was found that the highest values of indentation creep were achieved at the LDPE irradiated with dose of $33 \mathrm{kGy}$ (by $31 \%$ lower than compared with non-irradiated LDPE). On the contrary, the highest values of the indentation creep were found for non-irradiated LDPE as is seen on Fig. 5. 


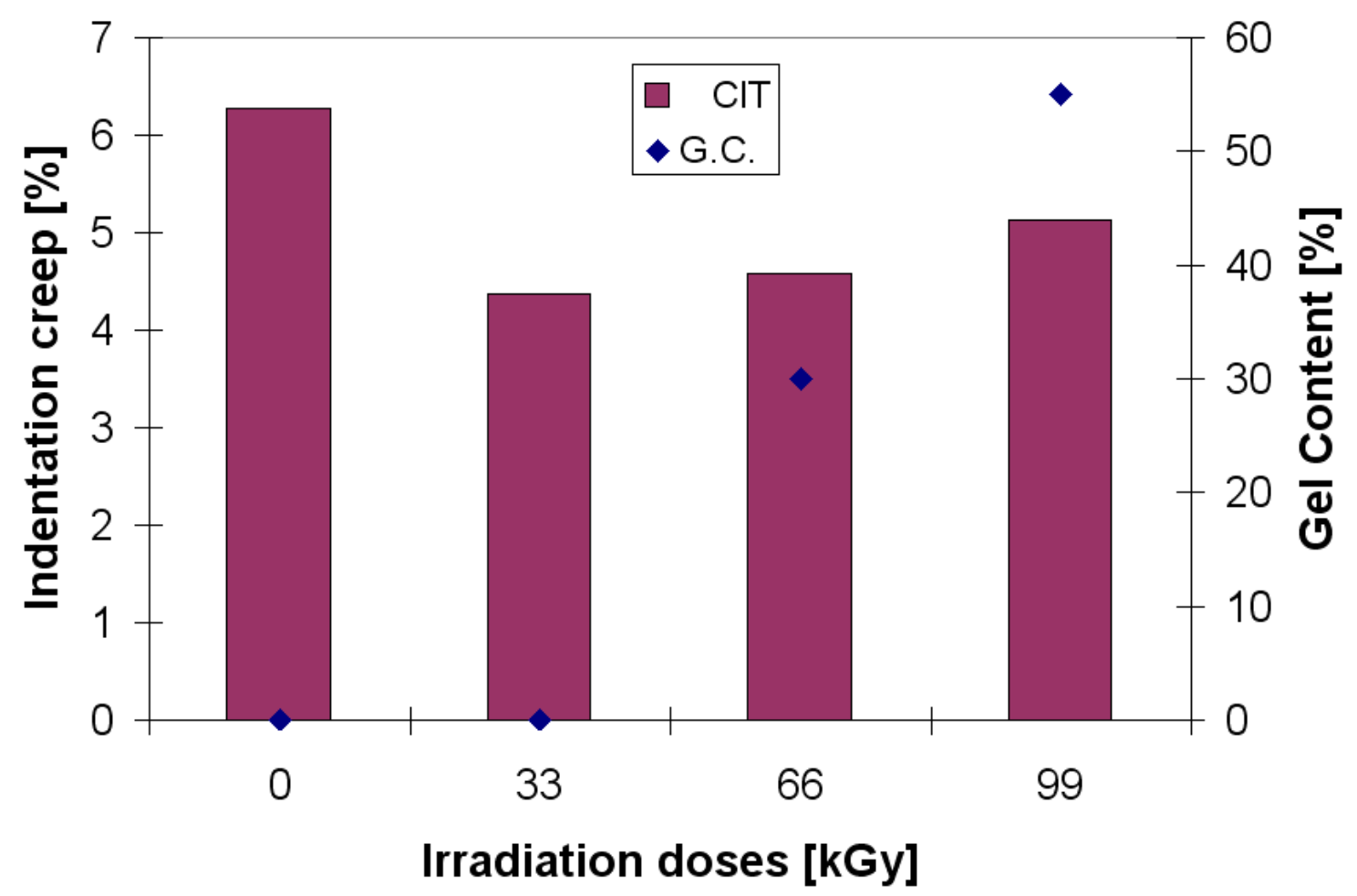

Fig. 5 Indentation creep $C_{I T}$ vs. irradiation dose of LDPE

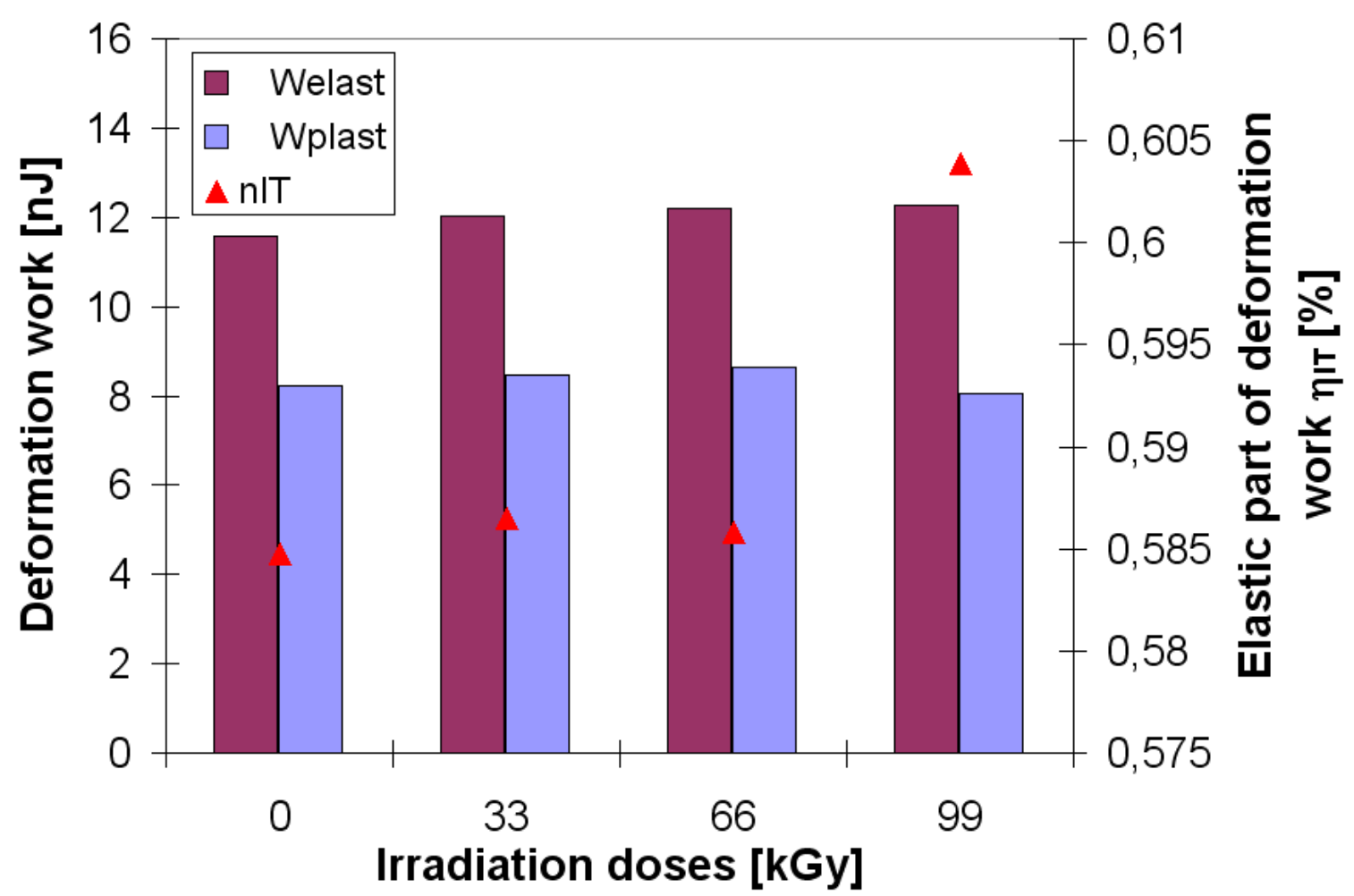

Fig. 6 Deformation work vs. irradiation dose of LDPE

Interesting results were found for elastic and deformation work. The lowest value of elastic work was measured for non-irradiated LDPE while the highest value of plastic deformation work was found at the radiation dose of $66 \mathrm{kGy}$. The lowest value at both deformation works was found when 
the lowest value of radiation dose of $99 \mathrm{kGy}$ was applied (Fig. 6). Also, the value of elastic part of indentation work $\eta_{\text {IT }}$ which provides information about the relaxation of the indent created in LDPE was the smallest for non-irradiated LDPE.

\section{Conclusion}

Very interesting results were obtained for irradiation modified LDPE. When comparing the irradiated and non-irradiated LDPE it was apparent that the values of indentation hardness, elastic modulus considerably decreased, in some cases even by $31 \%$ at the irradiation dose of $33 \mathrm{kGy}$. Improvement of mechanical properties in micro and macro scale of radiated LDPE has a great significance also for industry. The modified LDPE shifts to the group of materials which have considerably better properties. Its micromechanical properties make LDPE ideal for a wide application in the areas where higher resistance to wear, creep are required. Commonly manufactured LDPE can hardly fulfill these criteria.

\section{Acknowledgment}

This paper is supported by the internal grant of TBU in Zlin No. IGA/FT/2014/016 funded from the resources of specific university research and by the European Regional Development Fund under the project CEBIA-Tech No. CZ.1.05/2.1.00/03.0089 and Technology Agency of the Czech Republic as a part of the project called TA03010724 AV and EV LED luminaire with a higher degree of protection.

\section{References}

[1] G. Zamfirova, V. Gaydarov, T. Zaharescu, L. G. Silva, Microindentation study of Electron Beam Irradiated Polyamide Samples, Chemicke Listy, 104 (2010), 283-286.

[2] A. Bolshakov and G.M. Pharr, Influences of pile-up on the measurement of mechanical properties by load and depth sensing indentation techniques, Journal of Materials Research. 13, (1998), 1049-1058.

[3] W.C. Oliver, G.M. Pharr, Measurement of Hardness and Elastic Modulus by Instrumented Indentation, Journal of Materials Research 19 (1), (2004), 1564 - 1583.

[4] D. Manas, M. Hribova, M. Manas, M. Ovsik, Stanek, Effect of Beta Irradiation on Morfology and Microhardness of Polypropylene Thin Layers, Thin Solid Films 530, (2013), 49-52.

[5] Rajatendu Sengupta, S. Sabharwal, V. K. Tikku, Alok K. Somani,Tapan K. Chaki, Anil K. Bhowmick, Effect of ambient-temperature and high-temperature electron-beam radiation on the structural, thermal, mechanical, and dynamic mechanical properties of injection-molded polyamide-6,6, Journal of applied polymer science,99 (4), (2006), 1633 -1644

[6] M. Ovsik, D. Manas, M. Manas, M. Stanek, M. Hribova, K. Kocman, D. Samek, Irradiated Polypropylene Studied by Microhardness and WAXS, Chemicke listy, 106 (2012), 507-510.

[7] A. Pusz, K. Michalik, Creep damage mechanisms in gas pipes made of high density polyethylene,2009 Archives of Materials Science and Engineering 36 (2), pp. 89-95 